\title{
Tedaviye dirençli glokom olgularında seton implantasyonu sonuçlarımız
}

\section{Results of seton implantation in refractory glaucoma \\ Raşit Kılıç*, Ertuğrul Mirza, Kuddusi Erkılıç, Sarper Karaküçük, Osman Ahmet Polat, Ayşe Öner}

Göz Kliniği (Dr. R. Kılıç), Sivas Numune Hastanesi, TR-58040 Sivas, Göz Hastalıkları Anabilim Dalı (Prof. Dr. E. Mirza, Prof. Dr. K. Erkılıç, Prof. Dr. S. Karaküçük, Dr. O. A. Polat, Prof. Dr. A. Öner), Erciyes Tıp Fakültesi, TR-38039 Kayseri

\section{Özet}

Amaç. Medikal tedavi ile kontrol altına alınamayan glokomlarda seton implantasyonu sonuçlarını değerlendirmek. Yöntem. Kliniğimizde, Ocak 2004-Ocak 2011 tarihleri arasında medikal tedaviyle kontrol altına alınamayıp seton implantasyonu yapılan 123 glokom hastasından, dosya bilgilerine ulaşılan ve düzenli takiplerine gelen 31 olgunun dosya bilgileri retrospektif olarak incelenmiştir. Bulgular. 24 olguya neovasküler glokom, 4 olguya üveitik glokom, 2 olguya afakik glokom, 1 olguya psödoeksfolyatif glokom tanısı ile seton implantasyonu yapılmıştır. 25 olguda Ahmed, 3 olguda Molteno, 2 olguda Baerveldt, 1 olguda Keiki Mehta implantı kullanılmıştır. Ameliyat öncesi göz içi basıncı ortanca değeri $40 \mathrm{mmHg}$ (23-66) olarak bulunmuştur. Olguların takip sürelerinin ortanca değeri 10 ay (3-78) olarak saptanmıştır. Son kontroldeki GİB ortanca değeri 15,5 mmHg (6-67) olarak bulunmuştur. Ameliyat sonrası komplikasyonlar; 3 olguda kronik hifema, 1 olguda hifema ve hipotoni, bir olguda hipotoni ve sonrasında ftizis bulbi, 1 olguda ağrılı göz nedeni ile evisserasyon, 1 olguda epiretinal membran, 1 olguda lokalize endotelyal yetmezlik görülmüştür. Sonuç. Seton implantasyonu medikal tedaviye dirençli glokom olgularında etkili bir tedavi yöntemidir.

Anahtar sözcükler: Glokom, seton implantları

\begin{abstract}
Aim. To evaluate our glaucoma tube implantation results for glaucoma cases that cannot be controlled with medication therapy. Method. The records of 31 cases whose medical records could be reached and and who could come to regular follow up visits among 123 patients that applied to our clinic between January 2004-January 2011 with refractory glaucoma for medical therapy were evaluated retrospectively. Results. Glaucoma tube implantation was performed with diagnosis of neovascular glaucoma in 24 cases, uveitic glaucoma in 4 cases, aphakic glaucoma in 2 cases, pseudoexfoliation glaucoma in 1 case. Ahmed valve for 25 cases, Molteno for 3 cases, Baerveldt for 2 cases, keiki mehta for one case were implanted. Preoperative intraocular pressure median value was $40 \mathrm{mmHg}$ (23-66). The median value of follow up duration was found to be 10 months (3-78). The median value of intraocular pressures for last follow up visit was $15.5 \mathrm{mmHg}$ (6-67). As postoperative complications, chronic hyphema in 3 cases, hypotony and hyphema in 1 case, hypotony and following phthisis bulbi in 1 case, painful eye and following evisceration in 1 case, epiretinal membrane in 1 case, endothelial failure in 1 case were observed. Conclusion. Glaucoma tube implantation is efficient alternative treatment method for refractory.
\end{abstract}

Keywords: Glaucoma, seton implants

Geliş tarihi/Received: 30 Eylül 2013; Kabul tarihi/Accepted: 12 Şubat 2014

*İletişim adresi:

Dr. Raşit Kılıç, Göz Kliniği, Sivas Numune Hastanesi TR-58040 Sivas. E-posta: kilicrasit@gmail.com 


\section{Giriş}

Seton implantları konvansiyonel tedavi ile göz içi basıncı kontrol altına alınamayan dirençli olgularda alternatif tedavi yöntemleridir. Bu yöntemler bir tüp yardımı ile ön kamara ve episkleral yüzey arasında şant oluşturma prensibine dayanmaktadır. Seton implantları akım kısıtlayıcı olan valvli ve akım kısıtlayıcı olmayan valvsiz olmak üzere ikiye ayrılmaktadır. Molteno ve Baerveldt s1k kullanılan valvsiz implantlarken, en sik kullanılan valvli implant ise Ahmed glokom valvidir [1-5]. Seton implantları genellikle üst temporale yerleştirilirler, ancak bu bölgenin anatomisi travma veya geçirilmiş cerrahiler nedeniyle bozulmuş olabilir. Bu durumlarda implantasyon yeri üst nazal veya alt kadran olarak düşünülebilir [6].

Neovasküler glokom, antifibrotik kullanılmış başarısız filtran cerrahisi geçirmiş açık açılı, kapalı açılı ve neovasküler glokomlu olgular, üveite sekonder glokom olguları, afakik ve psödofakik olgular, keratoplastiye sekonder glokom olguları tüp implantları için endikasyon teşkil etmektedirler [1]. Neovasküler glokom, medikal tedavi ve filtran cerrahinin başarı olasılığı düşük olduğu için tüp implantasyon endikasyonlarının başında gelmektedir [7, 8].

$\mathrm{Bu}$ makalede konvansiyonel medikal ve cerrahi tedavi ile kontrol altına alınamayan glokom olgularında seton implantasyonu sonuçları değerlendirilmiştir.

\section{Gereç ve yöntem}

Erciyes Üniversitesi Tıp Fakültesi Göz Hastalıkları Kliniği'nde Ocak 2004-Ocak 2011 tarihleri arasında medikal tedaviyle kontrol altına alınamayı seton implantasyonu yapılan 123 glokom hastasından, dosya bilgilerine ulaşılan ve düzenli takiplerine gelen 31 olgunun dosya bilgileri retrospektif olarak incelenmiştir.

Hastaların yaşları, cinsiyetleri, en iyi düzeltilmiş görme keskinlikleri, ön ve arka segment muayeneleri, glokom tipleri, göz içi basınçları (GIBB), ameliyat öncesi kullandıkları antiglokomatöz ilaçları, geçirdikleri oküler ameliyatlar kaydedilmiştir. Olgular, ameliyat sonras1 1 'inci gün, 1'inci hafta, 1'inci ay, 3'üncü ay ve daha sonra düzenli olarak 3 ay aralıklarla takip edilmişlerdir. Son kontrolde ölçülen GİB değerinin 5-21 mmHg arasında olması cerrahi başarı olarak belirlenmiştir. Ameliyat sonrası kontrollerde gerekli olgularda revizyon cerrahisi ve antiglokomatöz topikal ilaçlar tedaviye eklenilmiştir.

\section{Ameliyat tekniği}

Genel ve lokal anestezi altında üst temporal bulber konjonktiva ve tenon kapsülü forniks tabanlı açıldı. Dengeli tuz solüsyonu ile tüpün açık olup olmadığı kontrol edildi. Episkleral plak, limbustan 10-12 mm geride, üzerindeki deliklerden absorbe olmayan 5/0 sütür (Ethibond) ile skleraya tespit edildi. Tüp girişi için limbustan 1-2 mm geriden kornea içinde iris planına paralel olacak biçimde 23 gauge $(\mathrm{G})$ bıçak kullanılarak ön kamaraya girildi. Tüpün ucu ön kamarada $2-3 \mathrm{~mm}$ ve açıklığı yukarıda oblik olacak şekilde kesilerek ayarlandı ve düz bir forseps kullanılarak skleral tünelden geçirilip ön kamaraya yerleştirildi. Tenon ve konjonktiva 8/0 vikril sütür ile kapatılarak ameliyata son verildi.

\section{Bulgular}

Olguların 18'i $(\% 58,1)$ erkek, 13'ü $(\% 41,9)$ kadın olup yaş ortalaması 55,6 20,6 yıl (1085 yaş aralığı) olarak bulunmuştur. 21'i $(\% 67,7)$ sağ gözden, 10’u $(\% 36,2)$ sol gözden opere olmuşlardır. Takip süresinin ortanca değeri 10 ay (3-78) olarak saptanmıştır. Olguların 24'ünde $(\% 77,4)$ neovasküler glokom, 4'ünde $(\% 12,9)$ üveitik glokom, 2 'sinde $(\% 6,4)$ afakik glokom ve 1'inde $(\% 3,2)$ psödoeksfolyatif glokom mevcuttu. Ameliyat öncesinde olguların görme keskinliği 18 gözde p(-), 8 gözde el hareketi (EH), 2 gözde 1/2 metreden parmak sayma (mps), 2 gözde $1 \mathrm{mps}, 1$ gözde $3 \mathrm{mps}$ düzeyinde idi. Ameliyat sonrasında ise 23 gözde p (-), 5 gözde EH, 1 gözde $1 \mathrm{mps}, 1$ gözde $2 \mathrm{mps}, 1$ gözde de 0,2 olduğu saptanmıştır. Olguların tümü ameliyat öncesinde 4'lü antiglokomatöz topikal ilaç kullanmaktayd1. 
Ameliyat öncesi GIBB ortanca değeri $40 \mathrm{mmHg}$ (23-66) olarak bulunmuştur. Ahmed glokom valvleri neovasküler glokomlu 21 olgu, üveitik glokomlu 2 olgu, afakik glokomlu 1 olgu, psödoeksfolyatif glokomlu 1 olgu olmak üzere toplam $25(\% 80,6)$ olguda kullanılmıştır. Molteno implantı neovasküler glokomlu 2 olgu, üveitik glokomlu 1 olgu olmak üzere toplam $3(\% 9,6)$ olguda kullanılmıştır. Baerveldt implantı neovasküler glokomlu 1 olgu, üveitik glokomlu 1 olgu olmak üzere toplam $2(\% 6,4)$ olguda kullanılmıştır. Keiki Mehta implantı ise afakik glokomlu $1(\% 3,2)$ olguda kullanılmıştır.

Olguların tümünde \%64,5 oranında cerrahi başarı sağlanmıştır. Ahmed glokom valvi kullanılan 17 (\%68) olguda başarı sağlanırken, 8 (\%32) neovasküler glokomlu olguda başarısız olunmuştur. Molteno implantı kullanılan 1 neovasküler glokomlu olguda başarıl1, 1 neovasküler glokomlu ve 1 üveitik glokomlu olguda başarısız olunmuştur. Baerveldt implantı kullanılan 2 olguda da başarı sağlanırken, Keiki Mehta implantı kullanılan 1 olguda başarı sağlanamamıştır (Tablo 1). Tüm olgularda ameliyat sonrası son kontroldeki GïB ortanca değeri 15,5 mmHg (0-67) olarak bulunmuştur.

Tablo 1. İmplant tiplerine göre başarı oranları.

\begin{tabular}{|c|c|c|c|c|}
\hline & Bașarılı & & Başarısız & \\
\hline Implant tipi & Glokom tipi & $\mathbf{n}$ & Glokom tipi & $\mathbf{n}$ \\
\hline \multirow{4}{*}{ Ahmed glokom valve } & NVG & 13 & NVG & 8 \\
\hline & SAKG & 2 & & \\
\hline & Afakik glokom & 1 & & \\
\hline & PEX glokom & 1 & & \\
\hline \multirow{2}{*}{ Molteno implantı } & $\mathrm{NVG}$ & 1 & NVG & 1 \\
\hline & & & SAKG & 1 \\
\hline \multirow{2}{*}{ Baerveldt İmplantı } & SAKG & 1 & - & - \\
\hline & NVG & 1 & & \\
\hline Keiki mehda & - & - & Afakik glokom & 1 \\
\hline Toplam & & $20(\% 64,5)$ & & $11(\% 35,5)$ \\
\hline
\end{tabular}

NVG: Neovasküler glokom, SAKG: Sekonder açı kapanması glokomu, PEX: Psödoeksfoliasyon

Ahmed glokom valvi kullanılan 2 neovasküler glokomlu olguda revizyon ameliyatı yapılmış, bir tanesinde başarılı olunmuştur. Trabekülektomiden fayda görmemiş üveitik glokomlu bir olguya Molteno implantı yapılmış ancak başarı sağlanamamıştır. Bir neovasküler glokomlu olguda ise üst nazale ikinci bir Ahmed glokom valv implantasyonu yapıldıktan sonra GİB kontrol altına alınmıştır.

Ameliyat sonrası komplikasyonlar; $3(\% 9,6)$ olguda kronik hifema, $1(\% 3,2)$ olguda hifema ve hipotoni, $1(\% 3,2)$ olguda hipotoni ve sonrasinda ftizis bulbi, $1(\% 3,2)$ olguda ağrilı göz nedeni ile evisserasyon, $1(\% 3,2)$ olguda epiretinal membran, $1(\% 3,2)$ olguda tüpün endotele teması nedeni ile lokalize endotelyal yetmezlik ve korneal ödem geliştiği görülmüştür (Tablo 2).

Tablo 2. Ameliyat sonrası komplikasyonlar.

\begin{tabular}{ll}
\hline Komplikasyonlar & n \\
\hline Kronik hifema & 3 \\
Kronik hifema ve hipotoni & 1 \\
Hipotoni ve fitizis bulbi & 1 \\
Epiretinal membran & 1 \\
Lokalize kornea ödemi & 1 \\
Eviserasyon & 1 \\
\hline
\end{tabular}




\section{Tartıșma}

Glokom, sık karşılaşılan göz hastalıklarından biridir ve kalıcı görme kaybının en önemli nedenlerindendir. Dirençli glokom olgularında seton implantasyonu etkin cerrahi yöntemlerden birisidir. Neovasküler glokom seton implantasyonu endikasyonlarının en başında yer almaktadır [1, 9-11]. Bu olgularda medikal tedavi yetersizdir ve klasik filtran cerrahisinin etkinliği ise sınırlıdır. Yine üveitik glokom, afakik ve psödofakik glokom, konjenital glokom, keratoplastiye sekonder glokom da seton implantasyonu endikasyonları arasındadır [1].

Seton implantların pars planadan implantasyonu özellikle neovasküler glokomlu olgularda arka segment hastalığını aynı seansta tedavi imkanı sağladığı için pars plana vitrektomi ile kombine olarak uygulanabilmektedir [11-17]. Ayrica kornea endotel yetmezliği durumlarında veya tüpün ön kamaraya yerleştirilmesi mümkün olmayan ön segment hastalığ 1 olan olgularda uygulanabilmektedir. Ancak koroid dekolmanı, retina dekolman1, vitreus hemorajisi, epiretinal membran, tüpün suprakoroidal veya subretinal alana kayması gibi komplikasyonlar görülebilmektedir [11-17].

Seton implantlarının, medikal tedavi ve filtran cerrahilere rağmen kontrol altına alınamayan olgularda GİB'i düşürmede etkili olduğu gösterilmiştir [3, 8]. Yalvaç ve ark. [9]'ları neovasküler glokomlu olgularda Ahmed glokom valvi ve Molteno implantı kullandıkları çalışmalarında bir yıllık başarı oranlarını sırasıyla $\% 63,2$ ve $\% 37$, beş yıllık başarı oranlarını \%25,2 ve \%29,6 olarak bildirmişlerdir. Budenz ve ark. [5]'ları Ahmed ve Baerveldt glokom implantlarını karşılaştırdıkları çalışmalarında ise sırasıyla \%83,6 ve \%86 sıklığında başarı sağladıklarını bildirmişlerdir. Acar ve ark. [18]'ları medikal tedaviye dirençli glokom olgularında Ahmed glokom valv implantasyonu uyguladıkları olgularda, birinci yıl sonunda başarı oranlarını \%66,7 olarak bildirmişlerdir. Taşkapılı ve ark. [10]'ları neovasküler glokomlu olgularda polipropilen ve silikon Ahmed glokom valvlerini iki ayrı grup olarak uygulamışlar ve birinci yıl başarı oranlarını sırasıyla \%64,2 ve \%66,6 olarak bildirmişlerdir. Bu çalışmada son kontrolde ölçülen GİB değerine göre $\% 64,5$ oranında başarı sağlanmıştır. 31 olgunun 25 tanesinde Ahmed glokom valvi kullanılmıştır ve bu olgularda \%68 oranında başarı elde edilmiştir.

Üveitik glokomlu olgularda seton implantlarının uzun dönem sonuçları oldukça iyidir [19-21]. Vuori, üveitik glokomlu olgularda Molteno implantı kullanmış ve 1 ve 4 yıllık başarı oranlarını sırasıyla $\% 97$ ve $\% 85$ olarak bildirmiştir [20]. Ozdal ve ark. [21]'ları çalışmalarında üveitik glokomlu olgulara Ahmed glokom valvi kullanmışlar ve 1 y1llık ve 2 yıllık başarı oranlarını sırasıyla $\% 94,4$ ve $\% 60$ olarak bildirmişlerdir. Bizim olgularımızda ise 4 üveitik glokomlu olgudan ikisine Ahmed glokom valvi, birisine Molteno implantı, birisine Baerveldt implantı kullanıldı. Molteno implantı başarısızlıkla sonuçlanırken diğer 3 implantta cerrahi başarı sağlanmıştır.

Psödofakik ve afakik glokom olgularında seton implantasyonu alternatif tedavi yöntemlerinden birisidir. Acar ve ark. [18]'ları 8 psödofakik olguya ve 1 afakik olguya Ahmed glokom valv implantasyonu uygulamışlar ve 7 psödofakik glokomlu olguda başarılı olurlarken, 1 psödofakik ve 1 afakik glokomlu olguda başarı sağlayamamışlardır. Bizde uygulanan 2 afakik glokomlu olgudan Ahmed glokom valvi kullanılan 1 olguda başarı sağlanırken, Keiki Mehta implantı kullanılan 1 olguda ise başarı sağlanamamıştır.

Seton cerrahisi sonrasında hifema, hipotoni, korneal ödem, tüp exposure, sı̆̆ ön kamara gibi çeşitli komplikasyonlar görülmektedir. Acar ve ark. [18]'ları, seton implantasyonu sonrasında en sik görülen komplikasyon olarak \%22,2 oranıyla hifemayı bildirmişlerdir. Taşkapılı ve ark. [10]'ları ise en sık görülen komplikasyonun hipotoni olduğunu bildirmişlerdir. Shen ve ark. [22]'ları hifemayı en sık karşılaşılan komplikasyon olarak gözlemlemişlerdir. Çalışmamızda en sık görülen komplikasyonlar kronik hifema $(\% 12,9)$ ve hipotoni $(\% 6,4)$ olmuştur. 
Sonuç olarak, dirençli glokomların kontrol altına alınması oldukça zordur. Valvli veya valvsiz seton implantları klasik filtran cerrahisi ve medikal tedaviye dirençli glokom olgularında tercih edilebilecek etkili bir tedavi yöntemidir.

\section{Kaynaklar}

1. Yalvaç IS, Kulaçoğlu DN. Glokom cerrahisinde seton implantları. Glo-Kat 2008; 3: 63-8.

2. Kim J, Allingham RR, Hall J, Klitzman B, Stinnett S, Asrani S. Clinical experience with a novel glaucoma drainage implant. J Glaucoma 2014; 23: 91-7.

3. Souza C, Tran DH, Loman J, Law SK, Coleman AL, Caprioli J. Long-term outcomes of Ahmed glaucoma valve implantation in refractory glaucomas. Am J Ophthalmol 2007; 144: 893-900.

4. Broadway DC, Iester M, Schulzer M, Douglas GR. Survival analysis for success of Molteno tube implants. Br J Ophthalmol 2001; 85: 689-95.

5. Budenz DL, Barton K, Feuer WJ, Schiffman J, Costa VP, Godfrey DG, Buys YM; Ahmed Baerveldt Comparison Study Group. Ahmed Baerveldt Comparison Study Group. Treatment outcomes in the Ahmed Baerveldt comparison study after 1 year of follow-up. Ophthalmology 2011; 118: 443-52.

6. Aksoy NÖ, Yalvaç IS, Şatana B, Ekşioğlu Ü, Kasım R, Aslan BS, Duman S. Alt kadrana yerleştirilen glokom implantları klinik uygulama sonuçları. TJO 2008; 38: 191-7.

7. Tsai JC, Feuer WJ, Parrish RK 2nd, Grajewski AL. 5-Fluorouracil filtering surgery and neovascular glaucoma. Long-term follow-up of the original pilot study. Ophthalmology 1995; 102: 887-92.

8. Kaya M, Ozbek Z, Yaman A, Durak I. Long-term success of Ahmed glaucoma valve in refractory glaucoma. Int J Ophthalmol 2012; 5: 108-12.

9. Yalvac IS, Eksioglu U, Satana B, Duman S. Long-term results of Ahmed glaucoma valve and Molteno implant in neovascular glaucoma. Eye (Lond) 2007; 21: 65-70.

10. Taşkapılı M, Yılmazlı C, Kocabora S, Şerefoğlu K, Özsütçü M, Göçmez E. Neovasküler Glokom Olgularında Polipropilen ve Silikon Ahmed Glokom Valvlerinin Karşılaştırmas. Glo-Kat 2008; 3: 37-41.

11. Faghihi H, Hajizadeh F, Mohammadi SF, Kadkhoda A, Peyman GA, RiaziEsfahani M. Pars plana Ahmed valve implant and vitrectomy in the management of neovascular glaucoma. Ophthalmic Surg Lasers Imaging 2007; 38: 292-300.

12. Kayıkçıŏlu Ö, Seymenoğlu G, Cinali M. Dirençli Glokomlarda Pars Plana Vitrektomi ile Kombine Pars Plana Molteno Tüp İmplantasyonu. Glo-Kat 2010; 5: 160-4.

13. Kaynak S, Tekin NF, Durak I, Berk AT, Saatci AO, Soylev MF. Pars plana vitrectomy with pars plana tube implantation in eyes with intractable glaucoma. Br J Ophthalmol 1998; 82: 1377-82.

14. Scott IU, Alexandrakis G, Flynn HW Jr, Smiddy WE, Murray TG, Schiffman J, Gedde SJ, Budenz DL, Fantes F, Parrish RK. Combined pars plana vitrectomy and glaucoma drainage implant placement for refractory glaucoma. Am J Ophthalmol 2000; 129: 334-41.

15. Lim KS, Allan BD, Lloyd AW, Muir A, Khaw PT. Glaucoma drainage devices; past, present, and future. Br J Ophthalmol 1998; 82: 1083-9.

16. de Guzman MH, Valencia A, Farinelli AC. Pars plana insertion of glaucoma drainage devices for refractory glaucoma. Clin Experiment Ophthalmol 2006; 34: 102-7.

17. Suárez-Fernández MJ, Gutiérrez-Díaz E, Julve San Martín A, Fernández-Reyes MF, Mencía-Gutiérrez E. Simultaneous pars plana vitrectomy and glaucoma drainage device implant. Arch Soc Esp Oftalmol 2010; 85: 97-102.

18. Acar BT, Hamurcu M, Sevim MŞ, Acar S. Tedaviye Dirençli Glokomda Ahmed Glokom Valfi İmplantasyonu. Glo-Kat 2010; 5: 189-94. 
19. Da Mata A, Burk SE, Netland PA, Baltatzis S, Christen W, Foster CS. Management of uveitic glaucoma with Ahmed glaucoma valve implantation. Ophthalmology 1999; 106: 2168-72.

20. Vuori ML. Molteno aqueous shunt as a primary surgical intervention for uveitic glaucoma: Long-term results. Acta Ophthalmol 2010; 88: 33-6.

21. Ozdal PC, Vianna RN, Deschenes J. Ahmed valve implantation in glaucoma secondary to chronic uveitis. Eye (Lond) 2006; 20: 178-83.

22. Shen CC, Salim S, Du H, Netland PA. Trabeculectomy versus Ahmed Glaucoma Valve implantation in neovascular glaucoma. Clin Ophthalmol 2011; 5: 281-6. 